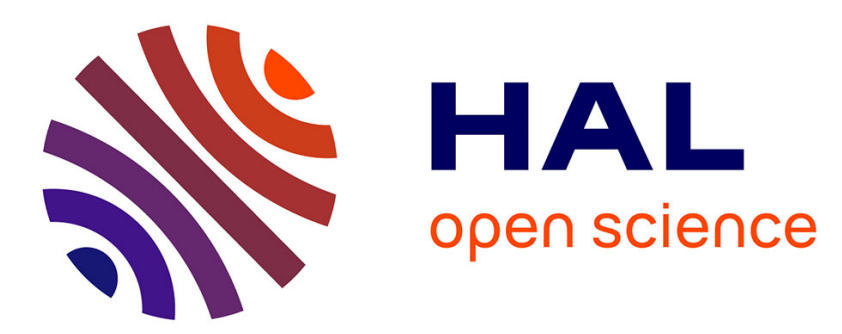

\title{
A STATISTICAL MODEL FOR DERIVING THE MICROSTRUCTURE PARAMETERS OF FINELY DISPERSED SYSTEMS FROM ATOM-PROBE ANALYSES
}

D. Blavette, S. Chambreland

\section{To cite this version:}

D. Blavette, S. Chambreland. A STATISTICAL MODEL FOR DERIVING THE MICROSTRUCTURE PARAMETERS OF FINELY DISPERSED SYSTEMS FROM ATOM-PROBE ANALYSES. Journal de Physique Colloques, 1986, 47 (C7), pp.C7-503-C7-508. 10.1051/jphyscol:1986784 . jpa00225980

\author{
HAL Id: jpa-00225980 \\ https://hal.science/jpa-00225980
}

Submitted on 1 Jan 1986

HAL is a multi-disciplinary open access archive for the deposit and dissemination of scientific research documents, whether they are published or not. The documents may come from teaching and research institutions in France or abroad, or from public or private research centers.
L'archive ouverte pluridisciplinaire HAL, est destinée au dépôt et à la diffusion de documents scientifiques de niveau recherche, publiés ou non, émanant des établissements d'enseignement et de recherche français ou étrangers, des laboratoires publics ou privés. 


\title{
A STATISTICAL MODEL FOR DERIVING THE MICROSTRUCTURE PARAMETERS OF FINELY DISPERSED SYSTEMS FROM ATOM-PROBE ANALYSES
}

\section{BLAVETTE and S. CHAMBRELAND}

\author{
UA-CNRS, Laboratoire de Microscopie Ionique, Faculté des \\ Sciences de Rouen, BP 67, F-76130 Mont-Saint-Aignan, France
}

\begin{abstract}
Résumé - Un modèle statistique simple pour déterminer les paramètres microstructuraux à partir des données de sonde atomique est décrit. Cette méthode permet de déduire la taille des particules, la fraction volumique et la véritable composition de précipités à partir des profils de concentration expérimentaux.

Abstract - A simple statistical model for determining the microstructural parameters from atom-probe data is described. This method allows to derive the particle size, the volume fraction as well as the actual composition of precipitats tes from composition profiles obtained experimentally.
\end{abstract}

\section{I - INTRODUCTION}

Because of its quantitative microanalysis capabilities with high spatial resolution, the FIM atom-probe is a well suitable technique for the investigation of early stages of decomposition $/ 1 /$. The number density as well as the mean size of very fine precipitates dispersed in a solid solution can be determined by field ion microscopy. In addition, selected area analysis of individual particles can be achieved.

However, the temperature conditions for obtaining a well visible contrast between phases are sometimes not compatible with those required for a quantitative analysis of the alloy. For instance atom-probe analyses of nickel base superalloys need low temperatures $(T=40 \mathrm{~K}$ ) where no visible contrast is observed $/ 2 /$.

Continuous random area investigations are much less tedious and can also provide informations on the material microstructure. However, the interpretation of concentration profiles requires statistical methods like autocorrelation analysis $/ 3 /$.

In the present paper we propose a simple model for the statistical analysis of atomprobe data for finely dispersed systems (spherical precipitates randomly distributed in a matrix). The aim of this study is to show the dependance of the mean apparent size, linear fraction and mean apparent composition of particles with the analysis parameters.

\section{II - PRINCIPLE OF THE METHOD AND RESULTS}

The basic hypotheses of the model are the following :

- The particles are spherical and homogeneously dispersed in the solid solution.

- The particle distribution is monomodal ; the mean size of precipitates is $\Phi$.

- The investigation of the material is similar to the analysis of a cylinder whose diameter is $\Phi_{a}$.

- Possible field induced variations in the local magnification associated to each phase are not taken into account.

- All particles are detected.

- The analysed volume is statistically representative of the microstructure of the material.

Mean apparent size

The following calculations are aimed at predicting the mean apparent size of particles 
as determined from concentration profiles. We simulate this parameter to the mean length $\langle 1\rangle$ which is intersected by the analysis cylinder (figure 1 ).

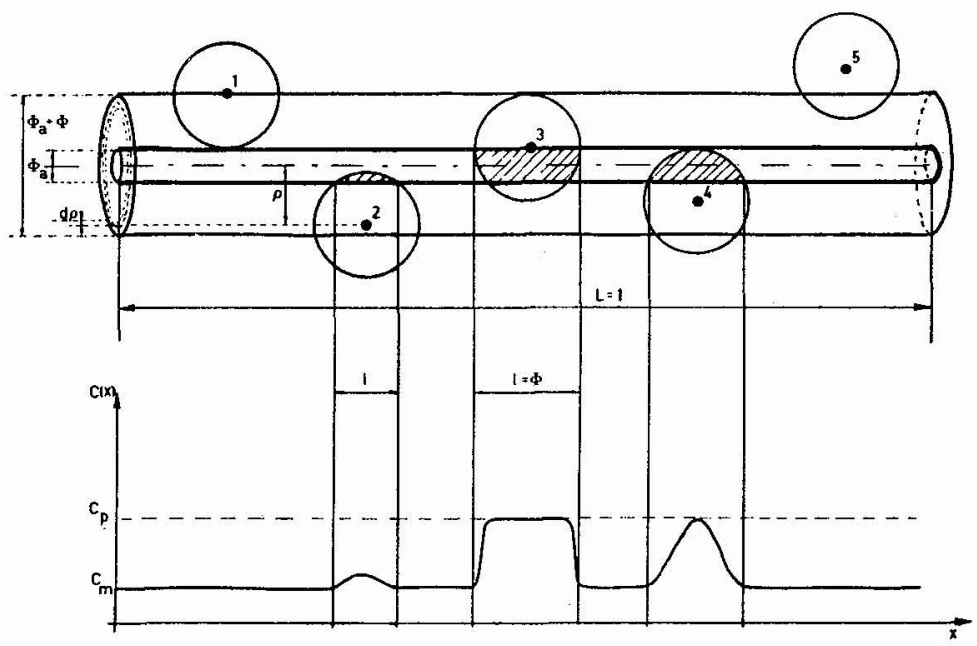

Figure 1 - Atom-probe analysis of a decomposed alloy. The particles are respectively being not detected (1), detected but not resolved (2), clearly resolved (3), close to be resolved (4), not detectable (5)

Let us consider the particles which are detectable. Only those precipitates the center of which is located inside a cylinder whose diameter is $\left(\Phi+\Phi_{a}\right)$ can be detected. If $\mathrm{N}_{\mathrm{v}}$ is the number density of particles, the expected number of precipitates which are analysed $\left(N_{1}\right)$ is, for a unit of length :

$$
\mathrm{N}_{1}=\mathrm{N}_{\mathrm{v}} \cdot \pi \cdot\left(\Phi+\Phi_{\mathrm{a}}\right)^{2} / 4
$$

the right-hand term refers to the scanned volume for a probed depth equal to unity. In order to calculate $\langle l\rangle$ two distinct cases have to be considered. For those particles the center of which is located inside the analysis cylinder, the intersected length is always equal to their diameter. The number of precipitates in such a case can be written as :

$$
\mathrm{N}_{1}(1=\phi)=\mathrm{N}_{\mathrm{v}} \cdot \pi \phi_{\mathrm{a}}^{2} / 4
$$

In contrast particles Iying from $\rho=\Phi_{a} / 2$ to $\rho=\left(\Phi+\Phi_{a}\right) / 2$ lead to lengths which may vary from $1=0$ to $1=\Phi$. It is easy to see that every particle whose center is located at a given distance $\rho$ from the tip axis is intersected over a constant length 1 . Elemental geometrical considerations give :

$$
\rho(1)=\left(\Phi_{a}+\sqrt{\Phi^{2}-1^{2}}\right) / 2
$$

The number of particles crossed by the cylinder over a length 1 within d1 is therefore :

with :

$$
\begin{aligned}
& \mathrm{dN}_{1}=\mathrm{N}_{\mathrm{v}} \cdot 2 \pi \rho(1) \mathrm{d} \rho \\
& \mathrm{d} \rho=\frac{\partial \rho}{\partial 1} \cdot \mathrm{d} I
\end{aligned}
$$

The mean length $\langle 1 *\rangle$ for those particles whose center is located outside the analysis cylinder $\left(\rho>\Phi_{a} / 2\right)$ but inside the scanned volume can now be easily obtained :

$$
\left\langle I^{*}\right\rangle=\frac{1}{\mathrm{~N}_{1}(1<\Phi)} \int_{1=\Phi}^{0} 1 \cdot \mathrm{dN}_{1}
$$


where $N_{1}(1<\Phi)$ is the number of particles per unit of length, leading to an apparent. length $1<\phi$. Substituting $d N_{1}$ by its expression as deduced from equations (3), (4), (5) one can write :

$$
\mathrm{N}_{1}(1<\Phi) .\left\langle 1^{*}\right\rangle=\frac{\pi \mathrm{N}}{2} \int_{1=\Phi}^{0}\left(1+\frac{\mathrm{n}}{\sqrt{1-1^{2} / \Phi^{2}}}\right) 1^{2} \mathrm{~d} 1
$$

with $\eta$ the analysis parameter defined as the ratio:

$$
\eta=\Phi_{a} / \Phi
$$

Integrating this expression (7) one gets :

$$
N_{1}(1<\Phi) \cdot\langle 1 *\rangle=\frac{\pi N_{v} \Phi^{3}}{2}\left(\frac{1}{3}+\frac{\pi \eta}{4}\right)
$$

The apparent mean length for every particle whatever their position inside the scanned volume may now be calculated :

$$
\langle 1\rangle=\frac{N_{1}\left(1\langle\Phi) \cdot\langle 1 *\rangle+N_{1}(1=\Phi) \cdot \Phi\right.}{N_{1}(1<\Phi)+N_{1}(1=\Phi)}
$$

with $N_{1}(1<\Phi)+N_{1}(1=\Phi)=N_{1}$; the tota1 number of detectable particles. Introducing the analysis parameter $n$ in the expressions (1) and (2) of $N_{1}$ and $\mathrm{N}_{1}(1=\Phi)$, this latter equation (10) can be manipulated to yield :

$$
\left\langle 1>=\frac{2}{3} \Phi \cdot\left(\frac{1+3 \pi n / 4+3 n^{2} / 2}{(1+n)^{2}}\right)\right.
$$

From iterative calculations, the actual particle diameter $\Phi$ may therefore be computed from the mean apparent length and the analysis parameter.

The ratio $\langle 1\rangle / \Phi$ is plotted versus $\eta$ in the figure 2 . For increasing values of this parameter, the apparent length varies from $2 \Phi / 3 \quad(n=0)$ to $\Phi(n \rightarrow \infty)$. An infinite probe diameter with respect to the precipitate size has obviously no significance for atom-probe analyses.

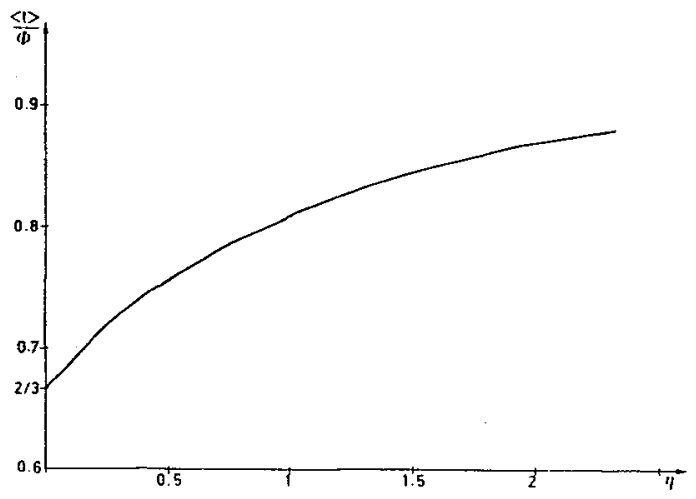

Figure 2 - The ratio of the mean apparent length $\langle 1\rangle$ to the precipitate diameter $\Phi$ as a function of the analysis parameter $n=\Phi_{a} / \Phi$.

Volume fraction and number density of particles

Another question of great interest is the determination of the volume fraction. When the particles are very fine, this parameter is difficult to be estimated from phase composition because of the limited accuracy with which the precipitate composition can be estimated. 
One method consists of deriving this parameter from the 1inear fraction of crossed particles $F_{\mathrm{I}}$. This parameter may be expressed as a function of the mean distance between parficles $\left\langle\mathrm{d}_{\mathrm{p}}\right\rangle$ :

$$
F_{L}=\frac{\langle 1\rangle}{\left\langle d_{p}\right\rangle}
$$

Considering the average scanned volume for one particle, one can easily write the number density as :

$$
\mathrm{N}_{\mathrm{v}}=1 /\left\langle\mathrm{d}_{\mathrm{p}}\right\rangle \cdot \pi\left(\Phi+\Phi_{\mathrm{a}}\right)^{2} / 4
$$

Now, the mean distance $\left\langle\mathrm{d}_{\mathrm{p}}\right\rangle$ can be related to the volume fraction $\mathrm{F}_{\mathrm{v}}$ :

$$
\mathrm{F}_{\mathrm{v}}=\pi \Phi^{3} \cdot \mathrm{N}_{\mathrm{v}} / 6
$$

Eliminating $N_{v}$ between (13) and (14), one easily obtains $\left\langle d_{p}\right\rangle$ as a function of $n$ :

$$
\left\langle d_{p}\right\rangle=2 \Phi / 3 F_{v} \cdot(1+\eta)^{2}
$$

Substituting this expression (15) in equation (12), the linear fraction can finally be written as :

$$
F_{L}=F_{V}\left(1+3 \pi n / 4+3 n^{2} / 2\right)
$$

This expression is obviously no longer valid when $F_{L}$ is close to unity. The figure $B$ shows the evolution of the ratio $F_{L} / F_{v}$ versus the analysis parameter $\eta$. This curve exhibits the rapid increase of $F_{L}$ with $\eta$ (for a given value of $F_{v}$ ).

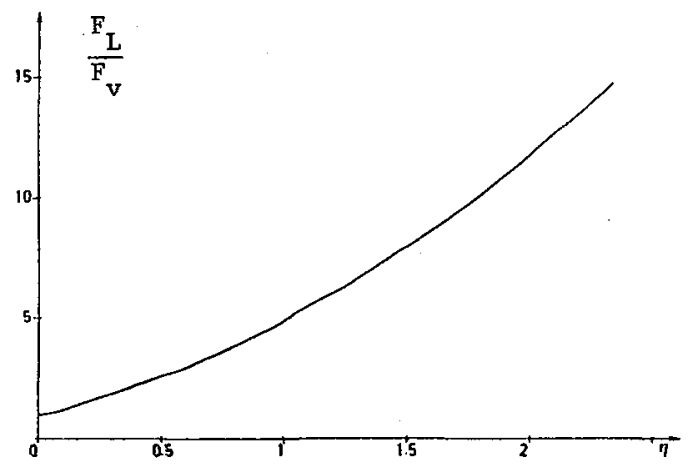

Figure 3 - The ratio of the linear fraction $\mathrm{F}_{\mathrm{L}}$ to the actual volume fraction versus the analysis parameter $n$

Mean apparent composition of particles

When particles are very fine, a lot of them cannot be resolved (figure 1). As a result their actual composition cannot always be attained. The composition of precipitates which are partially crossed on an edge by the analysis cylinder generally falls somewhere between the matrix composition and the precipitate one /5/. Due to the unavoidable statistical fluctuations, it is often difficult to decide, even from the shape of concentration profiles, whether the composition data are consistent or not.

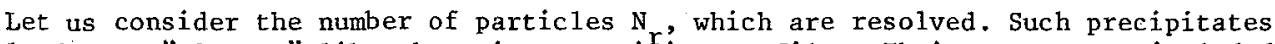
lead to a "plateau" like shape in composition profiles. Their center are included inside a cylinder the radius of which is :

so that :

$$
\rho_{\mathrm{r}}=\left(\Phi-\Phi_{\mathrm{a}}\right) / 2
$$

$$
\mathrm{N}_{\mathrm{r}}=\mathrm{N}_{\mathrm{v}} \cdot \pi\left(\Phi-\Phi_{\mathrm{a}}\right)^{2} / 4
$$


Introducing again the analysis parameter $\eta$, the fraction of resolved particles can be written as :

$$
R(n)=(1-n)^{2} /(1+n)^{2}
$$

The figure 4 shows for instance, that only $10 \%$ of detectable precipitates are statistically resolved for a spatial resolution $\Phi_{a}$ equal to half the particle diameter. In order to take advantage of the whole information it is desirable to predict the mean composition $\left\langle\mathrm{C}_{\mathrm{p}}^{\mathrm{i}}\right\rangle$ averaged over all particles whatever their position with respect to the analysis axis.

The analysis being consistent with the nominal composition $c_{N}^{i}$ of the material, one may write :

$$
C_{N}^{i}=F_{L}\left\langle C_{P}^{i}\right\rangle+\left(1-F_{L}\right) c_{m}^{i}
$$

where $c_{m}^{i}$ is the matrix concentration for the element $i$. Besides, the actual composition $C_{p}^{i}$ of precipitates is related to $C_{m}^{i}$ and $C_{N}^{i}$ by the
classical relation :

$$
\mathrm{C}_{\mathrm{N}}^{\mathrm{i}}=\mathrm{F}_{\mathrm{v}} \mathrm{C}_{\mathrm{p}}^{\mathrm{i}}+\left(1-\mathrm{F}_{\mathrm{v}}\right) \mathrm{C}_{\mathrm{m}}^{\mathrm{i}}
$$

Eliminating $C_{N}^{i}$ between equations $(20)$ and (21) and substituting the ratio $F_{L} / F_{V}$ by its expression (16), the actual composition $c_{p}^{i}$ may be finally expressed as :

$$
c_{p}^{i}=\left(1+3 \pi n / 4+3 n^{2} / 2\right)\left(\left\langle c_{p}^{i}\right\rangle-c_{m}^{i}\right)+c_{m}^{i}
$$

So far as the analysis parameter is known, one can therefore deduce the true composition of particles from the mean apparent one.

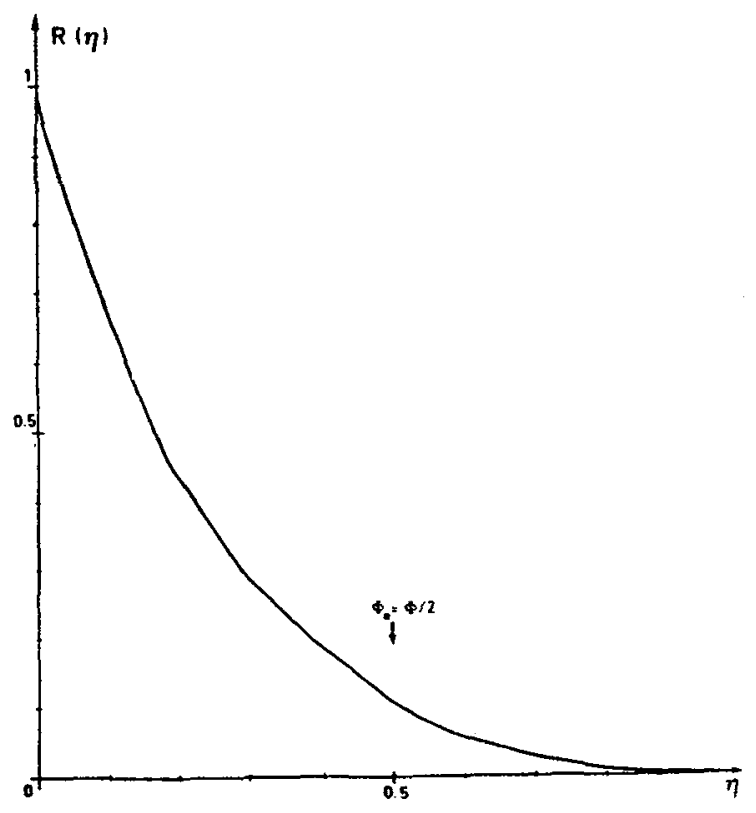

Figure 4 - The ratio of resolved particles as a function of the analys is parameter $n$. 
III - CONCLUSION

The model allows the derivation of the microstructural parameters such as the particle size, the volume fraction as well as the true precipitate composition even for very fine particles. Local magnification effects or even the non idea1 particle detectability should be taken into account in these calculations.

In addition, field emission specimen being often conical, one have also to include the reduction of the spatial resolution which is observed during the course of experiments (the analysed volume is rather a truncated cone than a cylinder $/ 4 /$ ).

The deviations from this ideal model will be discussed in a future paper.

\section{REFERENCES}

/1/ S. R. Goodman, S. S. Brenner and J. R. Low, JR Met. Trans. 4. (1973) 2371

/2/ D. Blavette, A. Boste1, J. M. Sarrau, Met. Trans. 16A (1985) 1703

/3/ J. Piller and H. Wendt, Proc. of 29th IFES, Almqvist and Wiksel $1_{\mathrm{h}}$ (1982) 265

14/ D. Blavette, A. Bostel, J. M. Sarrau and J. Gallot, Proc. of $29^{\text {th }}$ IFES, Almqvist

$15 / \mathrm{D}_{22} \mathrm{Blavette}$ and $\mathrm{S}$. Chambreland, Proc. of $32^{\text {nd }}$ IFES, J. de Physique, C2-47 (1985) 